\title{
Investigation of effectiveness of some vibration-based techniques in early detection of real-time fatigue failure in gears
}

\author{
Hasan Ozturk ${ }^{\mathrm{a}, *}$, Isa Yesilyurt ${ }^{\mathrm{b}}$ and Mustafa Sabuncu ${ }^{\mathrm{c}}$ \\ ${ }^{a}$ Research Assistant in Mechanical Engineering, Dokuz Eylul Universitesi, Muhendislik Fakultesi, 35100 Bornova, \\ Izmir, Turkey \\ ${ }^{\mathrm{b}}$ Mechanical Engineering, Usak Universitesi, Muhendislik Fakültesi, 64300 Usak, Turkey \\ ${ }^{\mathrm{c}}$ Mechanical Engineering, Dokuz Eylul Universitesi, Muhendislik Fakultesi, 35100 Bornova, Izmir, Turkey
}

Received 18 November 2008

Revised 2 September 2009

\begin{abstract}
Bending fatigue crack is a dangerous and insidious mode of failure in gears. As it produces no debris in its early stages, it gives little warning during its progression, and usually results in either immediate loss of serviceability or greatly reduced power transmitting capacity. This paper presents the applications of vibration-based techniques (i.e. conventional time and frequency domain analysis, cepstrum, and continuous wavelet transform) to real gear vibrations in the early detection, diagnosis and advancement monitoring of a real tooth fatigue crack and compares their detection and diagnostic capabilities on the basis of experimental results. Gear fatigue damage is achieved under heavy-loading conditions and the gearbox is allowed to run until the gears suffer badly from complete tooth breakage. It has been found that the initiation and progression of fatigue crack cannot be easily detected by conventional time and frequency domain approaches until the fault is significantly developed. On the contrary, the wavelet transform is quite sensitive to any change in gear vibration and reveals fault features earlier than other methods considered.
\end{abstract}

Keywords: Real time gear fatigue, gear vibration, cepstrum, continuous wavelet transform

\section{Nomenclature}

$\begin{array}{ll}a & \text { dilation } \\ b & \text { translation } \\ C W T & \text { continuous wavelet transform } \\ C_{h} & \text { admissibility condition } \\ C_{p}(\tau) & \text { power cepstrum } \\ E & \text { signal energy } \\ f & \text { frequency } \\ f_{0} & \text { wavelet centre frequency } \\ h(t) & \text { mother wavelet } \\ H(f) & \text { Fourier transform of } h(t) \\ t & \text { time instant } \\ x(t) & \text { analysed time signal } \\ * & \text { complex conjugation }\end{array}$

${ }^{*}$ Corresponding author. Tel.: +90 232 3883138/104; Fax: +90 232 3887868; E-mail: hasan.ozturk@ deu.edu.tr. 


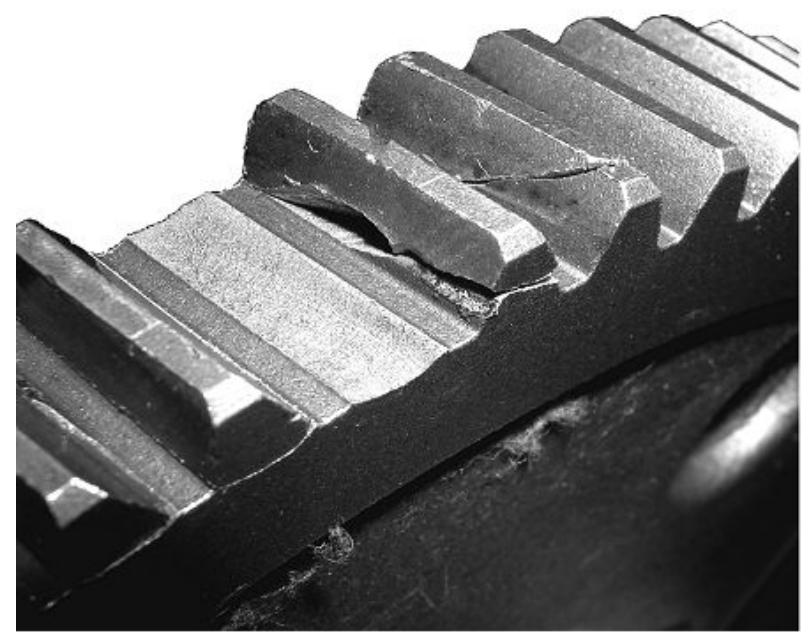

Fig. 1. Typical example of a tooth bending fatigue crack.

\section{Introduction}

Maintenance costs comprise a major part of the total operating expenses for all manufacturing or production plants and, depending on the specific industry, maintenance costs could be up to 60 percent of the cost of goods produced. For example, in food related industries, an average maintenance cost is about 15 percent of the cost of goods produced, whereas it represents up to 60 percent of the total production costs for iron and steel, pulp and paper, and other heavy industries [1]. Reducing the maintenance costs, preservation of investments, and effective operation of the plant can, in the long term, only be ensured by the application of a continuous and effective maintenance policy together with the prediction of probable defects beforehand and taking the necessary measures.

Gearboxes are widely utilised in industrial settings to transmit power or rotary motion whilst maintaining intended torque and angular velocity ratio together with smooth motion and high efficiency. These criteria are usually achieved unless a gear is defective. In order to minimize gearbox downtime and to avoid performance degradation, a practical and robust monitoring system is needed to provide early warnings of malfunction or possible damage, which may lead to sudden or even catastrophic failures. Such a monitoring system can also be used to carry out preventive maintenance of gearboxes to save time in repairs by identifying the damaged components without the need for routine shutdowns and manual inspections.

A gear set may exhibit a variety of failure modes affecting either all gear tooth surfaces (e.g. scuffing, pitting, plastic flow, abrasive wear) or a single tooth (or a few teeth) on a gear (e.g. tooth fracture due mainly to bending fatigue, gear rim failure) [2]. Of these faults, tooth fracture, which is one of the most dangerous failures, generally initiates either at the root or on the surface of a tooth [3], spreads rapidly into the gear body, and finally results in either complete or partial tooth breakage as shown in Fig. 1. The surprising feature is that tooth breakage can occur and may not be noticed until a routine strip down. In the end, the major hazard may become inevitable if the broken tooth attempts to go through the mesh and may jam the drive.

Over the last two decades, vibration analysis is extensively used as the basis for fault detection in gearboxes and condition indicating information is obtained by employing different techniques including: conventional signature analysis in time and frequency domains [4-7], signal demodulation [8-10], and cepstrum [11,12] techniques. Of these methods, cepstrum analysis is used for a variety of purposes and proven to be a powerful technique for fault detection and monitoring, removal of unwanted signal components from the vibration signal, detection of periodic structures in the signal, and many others.

A variety of joint time-frequency methods has also been used for the analysis of vibration signals to extract useful diagnostic information. In contrast to the other techniques considered, combined time-frequency methods present signal energy as a function of both time and frequency simultaneously and can be performed with either constant or varying time-frequency resolution. The most frequently used time-frequency methods are namely Short 
Time Fourier Transform (STFT) [13-18], Wigner - Ville distribution (WV) [13,19-26], Choi-Williams distribution (CWD) [13,27,28], Instantaneous Power Spectrum distribution (IPS) [13,29-32], Smoothed Instantaneous Power Spectrum distribution (SIPS) [32], and Continuous Wavelet Transform (CWT) [14,15,26,31,33-49].

Of these time-frequency methods, the STFT and CWT perform a linear decomposition of the analyzed signal, and therefore do not cause any interference. The STFT employs a constant window size during the analysis and, hence, results in a constant time - frequency resolution. However, the CWT performs a decomposition of the analyzed signal into a set of waves (or wavelets), which are derived from a single wavelet, and wavelets at different frequencies are generated by introducing dilation into the analyzing wavelet. A large window is used for low frequency estimates with poor time resolution, whereas the window automatically narrows at high frequencies, improving time resolution of the transform, but the frequency resolution deteriorates according to the uncertainty principle [34,46]. Therefore, the wavelet transform provides a good compromise between localization and frequency resolution.

This paper presents the applications of vibration-based techniques (i.e. conventional time and frequency domain approaches, cepstrum, and wavelet transform) to real gear vibrations in the early detection, diagnosis and advancement monitoring of a real tooth fatigue crack in helical gears. First of all, a brief theoretical background is given about the cepstrum and continuous wavelet transform and then the gear test rig and experimental setup are detailed. After that, real vibration data is monitored continuously from a double-stage industrial gearbox under heavy-loading conditions and the gearbox is allowed to run until the gears have suffered badly from complete tooth breakage which occurred after 15 minutes. The averaged gear vibrations monitored at two-minute intervals are used in the time domain analysis and it was found that early fault indications are revealed at the 10th minute of the running test. In addition, the residual signal is constructed by removing the regular meshing components together with their first order sidebands from the synchronous averaged signal and it was found that the removal of the meshing tones does not help very much with the early detection of fault, but only improves the visibility of fault features. In frequency domain analysis, the gear vibrations detected at two-minute intervals and averaged over five pinion rotations (which yields a resolution of $5.2 \mathrm{~Hz}$ ) are considered. Similar to the time signature analysis, the early indication of fault is also revealed at the 10th minute of the operation by the generation of a large number of sidebands at low frequency regions. Extending the testing time further makes the resulting fault symptoms more distinctive in either domain. Moreover, the same vibration data used for the spectral analysis is considered for the cepstrum analysis and it was found that cepstrum analysis reveals the fault symptoms earlier (i.e. at the 8th minute) than both the conventional signature and spectral analyses do. In the cepstral analysis, the presence of a local fault gives rise to the amplitudes of the high-quefrency rahmonics, whereas the low quefrency rahmonics exhibit diminishing amplitudes when the testing time is prolonged. Finally, the wavelet transform is applied to the residual gear vibrations and it was found that it is superior to the other techniques in the early detection, diagnosis, and advancement monitoring of fatigue damage in gears. The fault symptoms are revealed on the maps of wavelet transform as early as the 5th minute of the running test. As the testing time is extended, fault features are strengthened at the same gear positions where the defective tooth (or teeth) is in mesh and their effect is seen across a large frequency range.

\section{Theoretical background}

\subsection{Cepstrum analysis}

Although conventional time and frequency domain approaches can routinely be used to reveal fault indicating information in the gear vibration signal, there are some situations in which neither analysis enhance those features of the signal which characterise a fault. Vibration monitored on a healthy gearbox generally exhibits predominant frequency peaks at tooth-meshing frequency and its multiple harmonics together with some sidebands located around the tooth-meshing components. During the normal operation of a gearbox in good condition, the number and magnitude of the resulting sidebands remain almost unchanged. Pronounced localised gear failures give localised amplitude distortion of the vibration signal and their effect is seen as low level sidebands spaced at the rotational frequency of the defected gear and extending across a wide frequency range. In addition, vibration in a gearbox is generated by the mating gears and its direct measurement at source is almost impossible. Gearbox vibration is generally monitored from the casing and hence it contains information not only from individual gear pairs, but 
also from the transmission path. Cepstrum analysis provides a powerful simplified representation, because it only responds to families of equally spaced spectral components (such as tooth-meshing harmonics or sidebands) reducing them to a single peak (possibly with a small number of rahmonics). Two forms of cepstrum, real (or power) and complex, are available and the power cepstrum (which is well suited and widely used for gearbox fault detection) is defined as follows [12]:

$$
C_{p}(\tau)=F F T^{-1}\left\{\log \left[X_{p}(f)\right]\right\}
$$

where $F F T^{-1}$ and $X_{p}(f)$ denote the inverse Fourier transform and power spectrum of the signal $x(t)$ respectively.

\subsection{Continuous wavelet transform}

Wavelets are mathematical functions which are well suited to expansion of non-stationary signals. They form the kernel of the wavelet transform, and enable a mapping of signals from the time domain into either the time-scale or the time-frequency domain. The continuous wavelet transform of a signal $x(t)$ can be expressed as the inner product of $x(t)$ with a wavelet function $h_{a, b}(t)[34,38]$.

$$
C W T(a, b)=\int_{-\infty}^{\infty} x(t) h_{b, a}^{*}(t) d t
$$

where $a \quad(a>0)$ and $b$ denote dilation and translation parameters respectively and * represents complex conjugation. The family $h_{a, b}(t)$ is constructed by dilation and translation of a function $h(t)$ (termed the analysing or mother wavelet) and is expressed as follows:

$$
h_{b, a}(t)=\frac{1}{\sqrt{a}} h\left(\frac{t-b}{a}\right)
$$

Using Parseval's theorem the total energy of a signal $x(t)$ can be expressed as follows:

$$
E=\int_{-\infty}^{\infty}|x(t)|^{2} d t=\frac{1}{C_{h}} \int_{-\infty}^{\infty} \int_{-\infty}^{\infty}\left|C W T_{x}(b, a)\right|^{2} \frac{d a d b}{a^{2}}
$$

where $E$ is the total signal energy and $C_{h}$ is a constant called the admissibility condition which is determined from the squared magnitude of the Fourier transform $|H(f)|^{2}$ of the wavelet function.

$$
C_{h}=\int_{-\infty}^{\infty}|H(f)|^{2} \frac{d f}{|f|}<\infty
$$

Mathematically, the wavelet transform offers flexibility in the selection of the analysing wavelet. The Morlet wavelet is used in this study because it is closely related to Fourier analysis and is therefore easier to understand. Besides, it gives good dilation and translation selectivity and is well adapted to the problem of locating abrupt changes in a signal. Moreover, the Morlet wavelet function is approximately progressive if its centre frequency is selected larger than $0.875 \mathrm{~Hz}$. The progressivity condition ensures that the wavelet transform does not produce any interference in the time domain between the past and future [35,39]. The Morlet wavelet in the time and frequency domains is defined as follows:

$$
\begin{aligned}
& h(t)=\exp \left(j 2 \pi f_{0} t\right) \exp \left(-t^{2} / 2\right) \\
& H(f)=\sqrt{2} \pi \exp \left(-2 \pi^{2}\left(f-f_{0}\right)^{2}\right)
\end{aligned}
$$

where $f_{0}$ is the wavelet centre (or oscillation) frequency and $t \in \Re$. The Morlet wavelet itself is not admissible, but appropriate selection of the wavelet centre frequency (e.g. $f_{0} \mathfrak{e} 0.875 \mathrm{~Hz}$ ) makes the Morlet wavelet admissible in practice $[34,38]$. 
Table 1

Specifications of the gears

\begin{tabular}{lcc}
\hline & $\begin{array}{c}\text { First stage } \\
(\text { Pinion/Wheel) }\end{array}$ & $\begin{array}{c}\text { Second stage } \\
(\text { Pinion/Wheel) }\end{array}$ \\
\hline Number of teeth & $20 / 38$ & $15 / 30$ \\
Normal module $(\mathrm{mm})$ & 1 & 1.75 \\
Pressure angle $\left({ }^{\circ}\right)$ & 20 & 20 \\
Profile shift $($ pinion/wheel) & $+0.666 /+0.345$ & $+0.338 /+0.437$ \\
Helix angle $\left({ }^{\circ}\right)$ & 30 & 15 \\
\hline
\end{tabular}

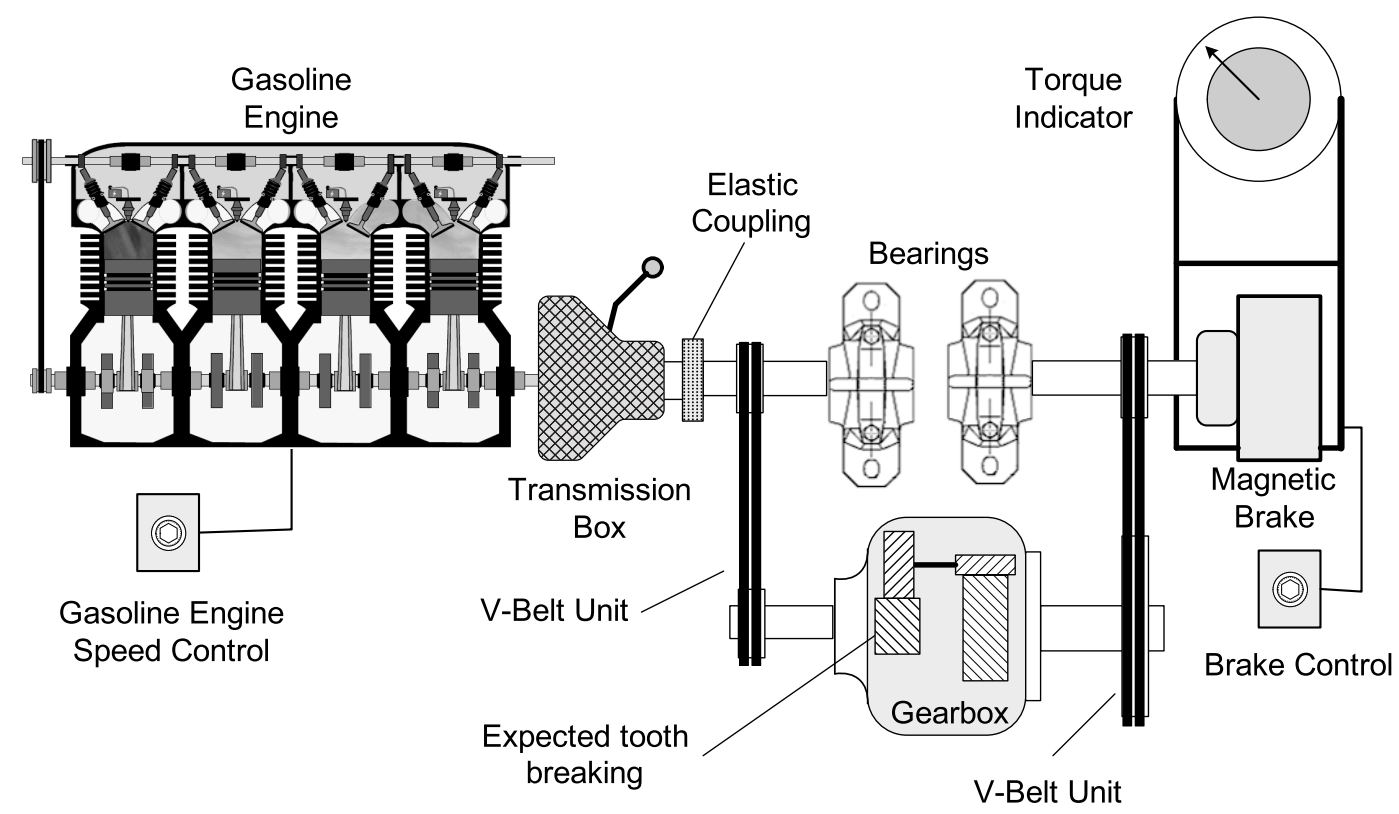

Fig. 2. Schematic representation of the test rig used for the real-time gear fatigue monitoring.

\section{Experimental setup and gear test rig}

A two-stage industrial gearbox, whose specifications are given in Table 1, was used for the real-time tooth breakage monitoring and a gasoline engine was used as a prime mover. All the gears were made of $21 \mathrm{NiCrMo} 2$ steel and were hobbed, case hardened and ground. The driving pinion at the first stage had 20 teeth meshing with a wheel of 38 teeth, whereas the other pinion at the second stage had 15 teeth meshing in a 1:2 ratio. The gasoline engine had four cylinders and was capable of producing a maximum power of $50 \mathrm{~kW}$ at approximately $3500 \mathrm{rpm}$. The power generated by the driving engine was passed through a four-stage gearshift unit, the output of which was then used to drive the test gearbox. In addition, a water-cooled magnetic brake, capable of producing an anti torque of up to $150 \mathrm{Nm}$, was connected to the output shaft of the gearbox to consume power and, consequently, to load gears within the gearbox. Moreover, an elastic coupling and V-belt units were employed in order to provide a much smoother power transmission through the gearbox and the other elements of the test rig. All these explanations are depicted in both Figs 2 and 3.

In order to achieve a tooth fatigue crack (and, consequently, a tooth breakage) within a shorter time, the face width of the pinion gear at the first stage was reduced to $4 \mathrm{~mm}$ from its original value of $10 \mathrm{~mm}$ as shown in Fig. 4 . This face width removal also permits the pinion to be tested at nearly twice of its nominal torque of $17 \mathrm{Nm}$.

During the fatigue test, the speed of the input pinion was set to nearly $1566 \mathrm{rpm}$ which yields a fundamental tooth-meshing frequency of $522 \mathrm{~Hz}$ for the first stage. The resulting vibrations were picked up by two accelerometers located around the bearing housing nearest to the input pinion as seen in Fig. 3. In addition, an inductive sensor producing one pulse per revolution was used to reference the angular position of the test gear. Both the accelerometer 


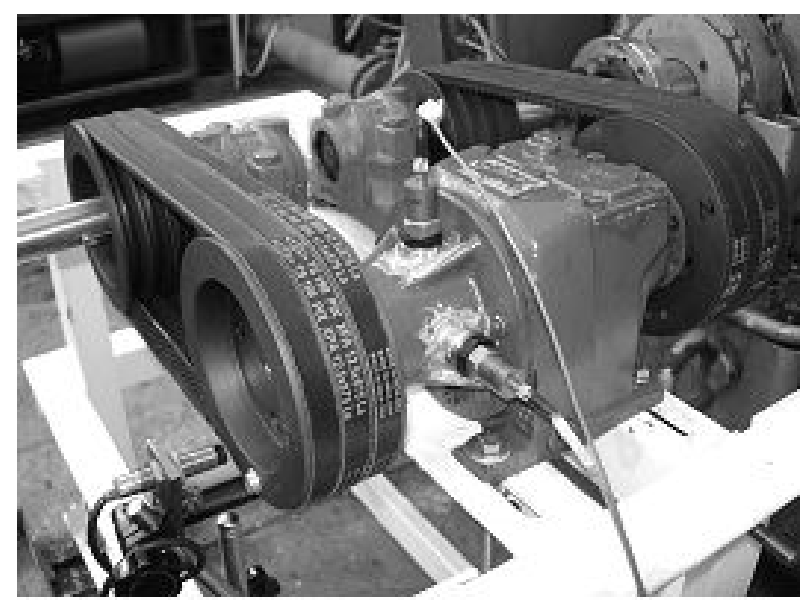

Fig. 3. Gearbox and accelerometers used.

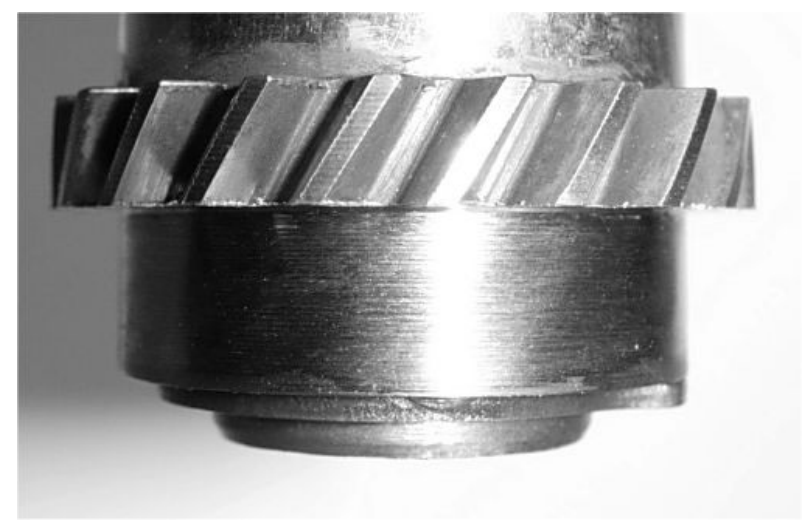

Fig. 4. Undamaged test pinion.

and reference positioning signals were sampled at $10 \mathrm{kHz}$ and recorded on a computer. The resulting vibration data was continuously collected until the gears suffered badly from tooth breakage. After that, it was split into 60-second blocks, each of which was then averaged over a desired number of input pinion rotations according to the nature of the analysis.

Before collecting the vibration data, the pinion was first run at $20 \%$ of the specified full load for nearly 2 hours to lessen the amount of surface asperities. At the end of this initial running period, the gear load was increased to twice its specified load (i.e. $34 \mathrm{Nm}$ ). Under the specified testing conditions, a complete tooth breakage was experienced at almost the 15th minute after the fatigue test commenced. After that, the gearbox was dismantled and it was found that the input pinion gear was severely damaged due to fatigue as shown in Fig. 5.

\section{Analysis of experimental results}

\subsection{Time and frequency domain analyses}

Figure 6 illustrates a complete time history of the resulting gear vibration detected until the end of fatigue life of the test gear. It can be seen that no change is observed in the amplitude of vibration until nearly the 10th minute of the test. After that, the vibration amplitude exhibits a gradual rise until the 14 th minute of the operation, which may 


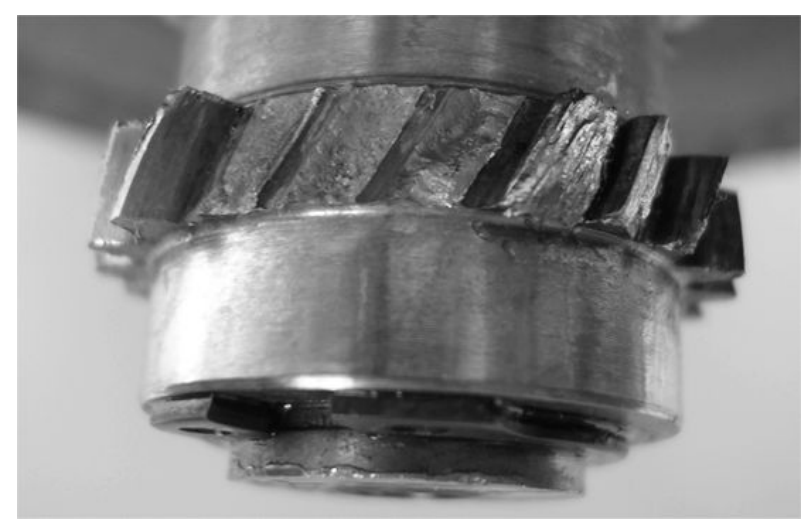

Fig. 5. Resulting fatigue damage on the test gear.

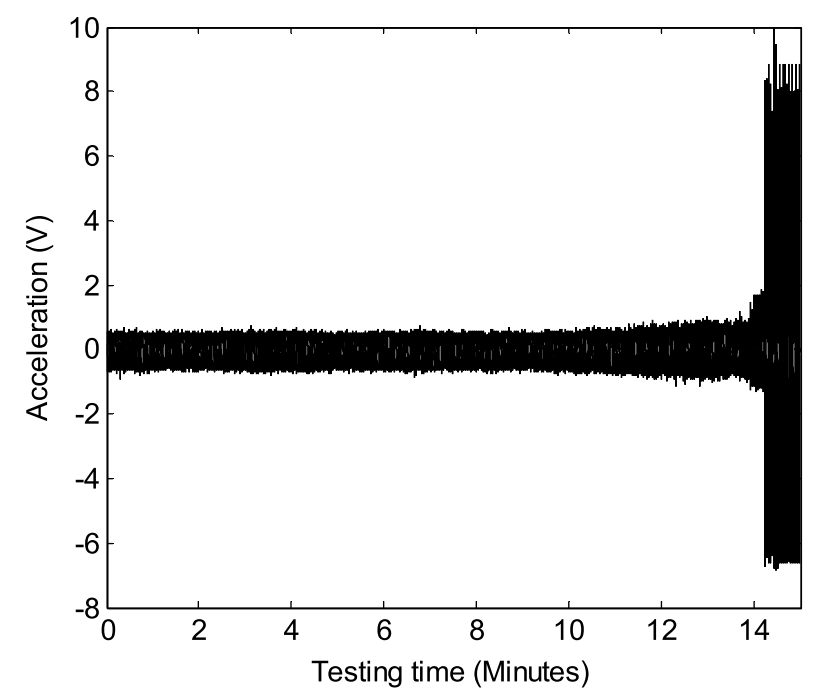

Fig. 6. Complete time history of gear vibration detected until the end of fatigue life of the test pinion.

be attributed to the onset and/or development of fatigue damage. When the time is further advanced, the amplitude of gear vibration increases drastically which is a clear indication of catastrophic gear damage.

Figure 7 shows the gear vibration accelerations averaged over one pinion rotation monitored at two-minute intervals during the fatigue test. It can be seen that the appearances of the gear vibrations are more or less similar to each other and amplitudes of vibrations exhibit no significant change until 10th minute of the test. At the 10th minute of the operation, the fault symptom is revealed in the time domain representation as an increase in vibration amplitude around the $120^{\circ}$ position. When the gears are allowed to run further, the amplitude of vibration is also remarkably increased between the $70^{\circ}$ and $120^{\circ}$ gear rotation positions signifying that the fatigue damage spreads over the neighbouring teeth due to improper meshing conditions. At the 14th minute of the test, the amplitude of vibration is remarkably increased at the same gear positions indicating that the gear has suffered badly from consequential tooth damages. After that, the test was stopped and the gearbox was dismantled and it was found that the input pinion gear was severely damaged and had lost three successive teeth completely and the following two teeth were partially damaged as seen in Fig. 5.

Figure 8 shows the spectra of the averaged gear vibrations with a resolution of $5.2 \mathrm{~Hz}$ detected at two minute intervals until the end of the test. The resulting spectra are mainly dominated by the tooth-meshing frequency components of vibration generated by the first gear stage since a large number of averaging over the input pinion gear was considered. Similar to the time domain representations shown in Fig. 7, the spectra of the gear vibrations 


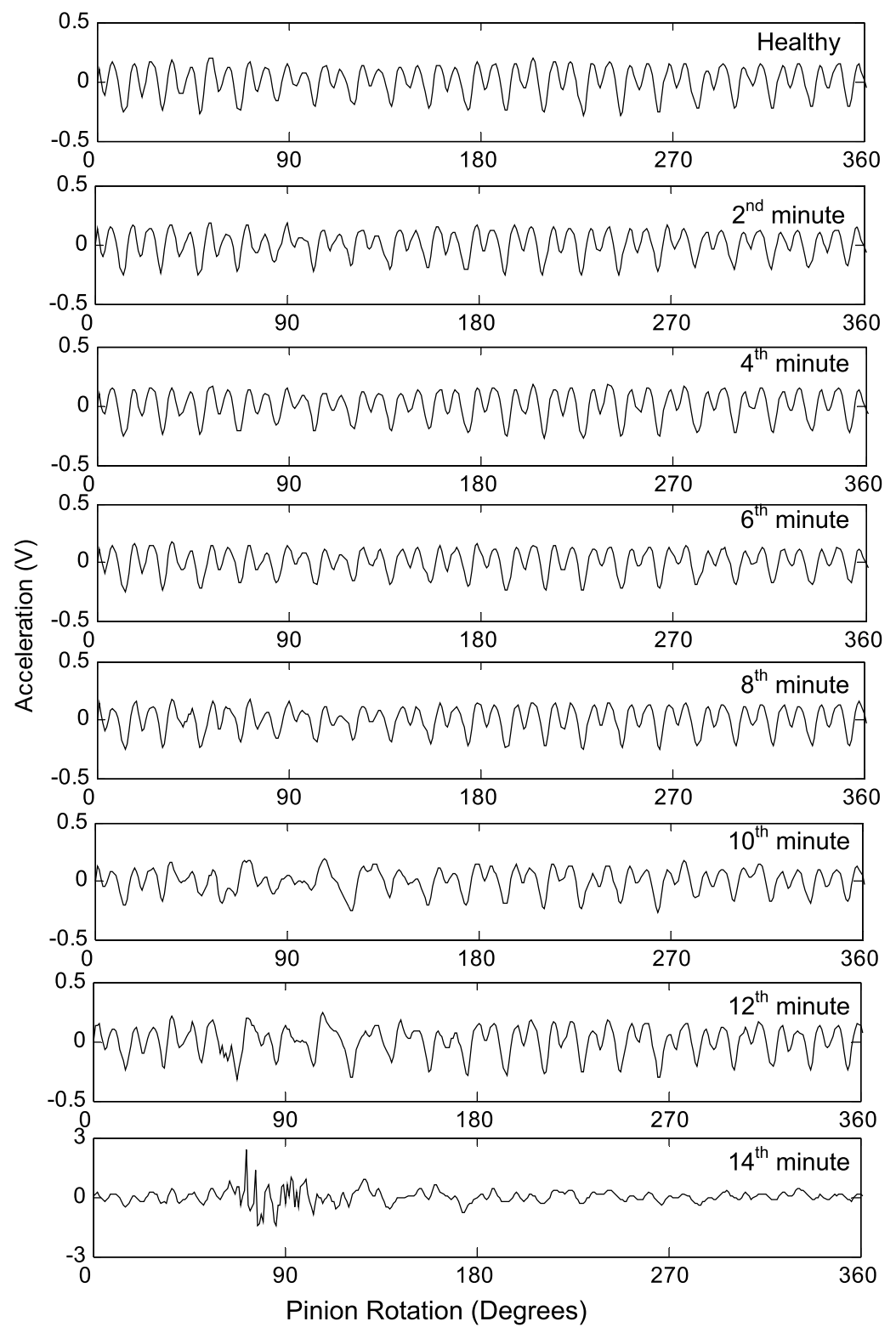

Fig. 7. Averaged gear vibration accelerations monitored at two-minute intervals during the fatigue test.

are also similar to each other and no symptoms of initiation or progression of fault can be seen until the 10th minute of the fatigue test. Beyond this time, some frequency activities become apparent in the low frequency regions as a reflection of weakened tooth/teeth due to fatigue damage. When the time is prolonged until the end of the fatigue test, the resulting tooth damage consequently gives rise to all frequency components and a large number of sidebands are generated across all frequencies (see the 14th minute of the test).

Figure 9 shows the averaged residual gear vibration accelerations for one pinion rotation detected at two-minute intervals during the fatigue test. The residual signature is constructed by removing the regular meshing components together with their first order sidebands (i.e. $26.1 \mathrm{~Hz}$ ) from the synchronous averaged signal. Similar to the averaged vibration signals, the averaged residual signals also reveal the presence of the weakened tooth/teeth at and after the 10th minute of the test. However, the fault symptoms in the residual signals are more distinct and more localised in time compared to those in the averaged vibration signals shown in Fig. 7. 


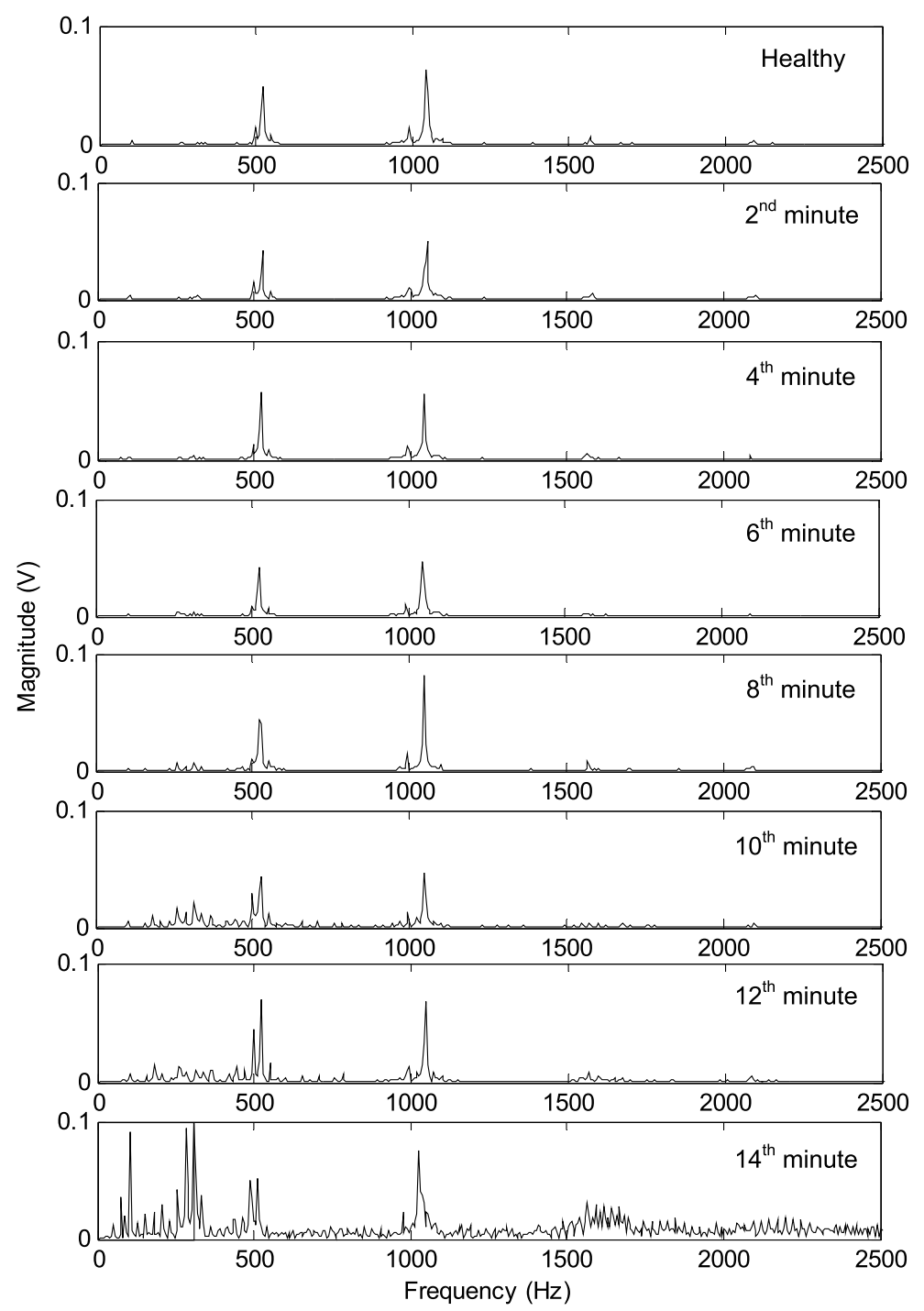

Fig. 8. Spectra of the gear vibrations monitored at two-minute intervals during the fatigue test.

In general, a local tooth defect weakens the tooth and reduces the mesh stiffness when that tooth is in mesh. This causes an impact of subsequent meshing teeth which changes the spikiness of the vibration signal associated with this mesh. Kurtosis (e.g. the fourth order statistical moment) is widely used to indicate spikiness of a signal and usually the higher the fault severity, the greater the value of Kurtosis. Figure 10 shows the variation of Kurtosis values of the residual vibrations recorded during the fatigue test. It can be seen that Kurtosis values do not exhibit any significant changes until the 9th minute of the test. After that, it yields an increasing trend between the 9th and 11th minutes of the operation which could be an indication of fault development. This increasing trend is not consistent until the end of the running test. When the gear teeth are severely damaged (i.e. at the 14th minute), the value of Kurtosis correspondingly increases.

\subsection{The application of cepstrum analysis}

For the cepstrum analysis, the vibration signals were averaged over five pinion rotations so that the resulting cepstra can exhibit at least two high-quefrency rahmonics corresponding to periodic events at the rate of pinion rotation. 


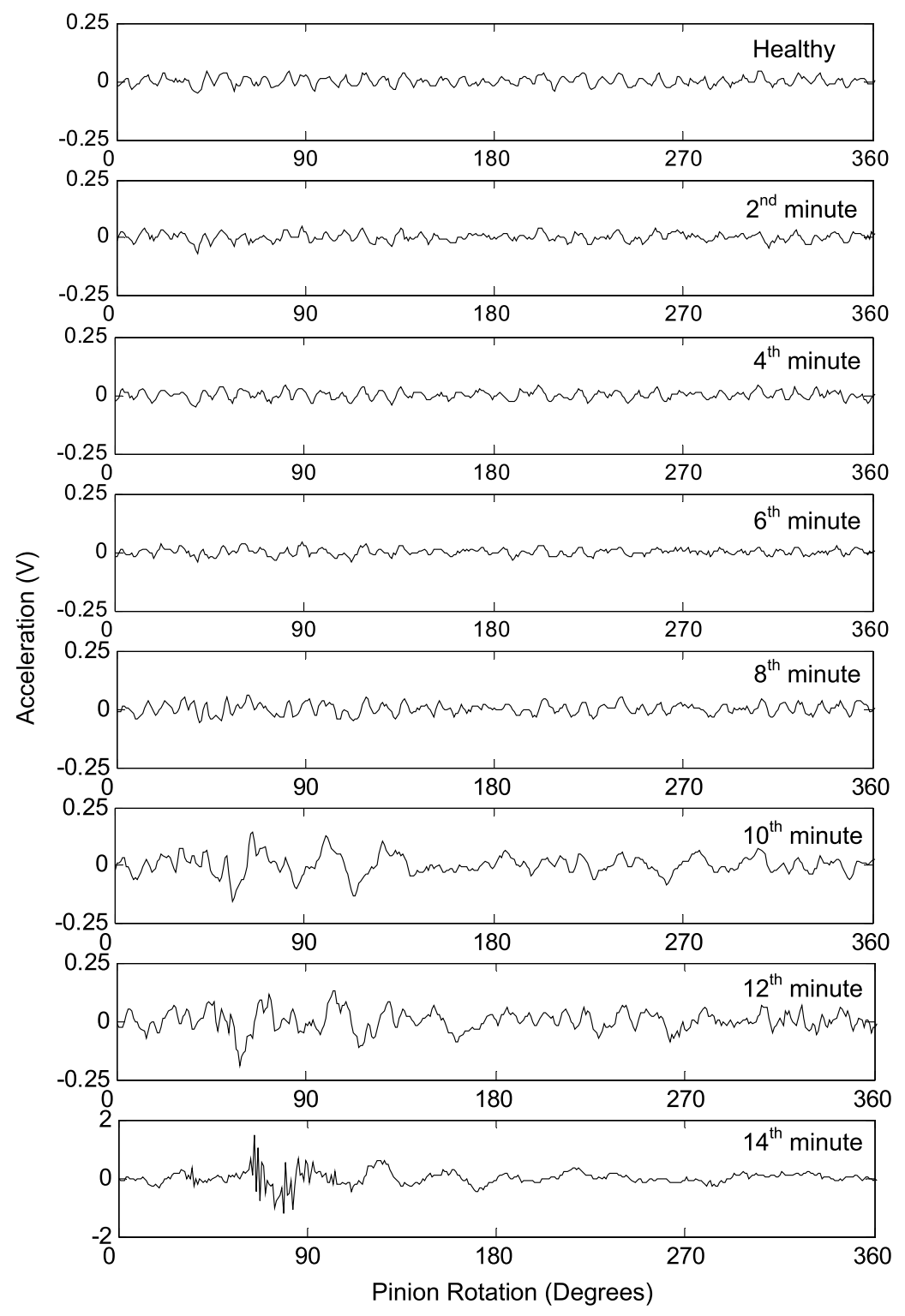

Fig. 9. Averaged residual gear vibrations monitored at two-minute intervals during the fatigue test.

Figure 11 shows the cepstra of the averaged gear vibration signals detected at two-minute intervals until the end of the fatigue test. It can be seen from the cepstrum of the vibration for the healthy gear that it consists of two families of rahmonics. The first family is densely clustered around the low-quefrency region, which represents high frequency periodic events in the gear vibration. The largest rahmonic within this family is located exactly at $1.9 \mathrm{msec}$ which corresponds to the period of consecutive tooth engagements. The second family has its fundamental at $38.5 \mathrm{msec}$ (which is the period for one rotation of the input pinion gear) and stems from gear imperfections which repeat themselves at the gear rotational rate.

For the first 6 minutes of the test, the resulting cepstra are quite similar to each other and the amplitudes of the high quefrency rahmonics remain almost unchanged. A notable change in the amplitude of the fundamental high quefrency rahmonic is observed at the 8th minute of the test (which is nearly $62 \%$ larger than that of the previous one) which could be an indication of fatigue crack. When the gears are allowed to run further, the second rahmonic of this fundamental also becomes apparent and the amplitudes of these high quefrency rahmonics are correspondingly 


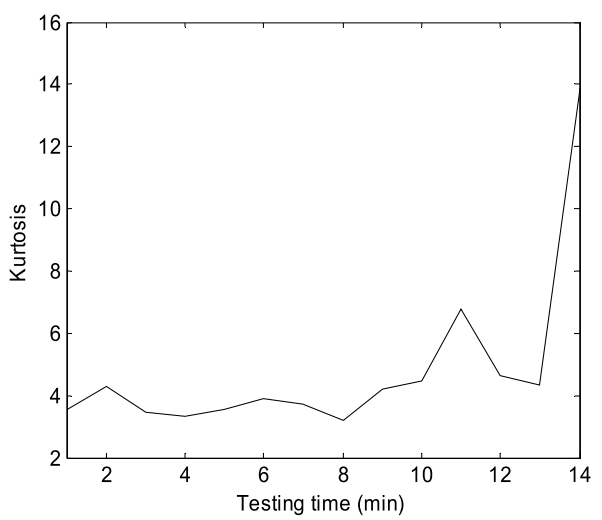

Fig. 10. Variation of kurtosis values of the residual vibrations recorded during the fatigue test.

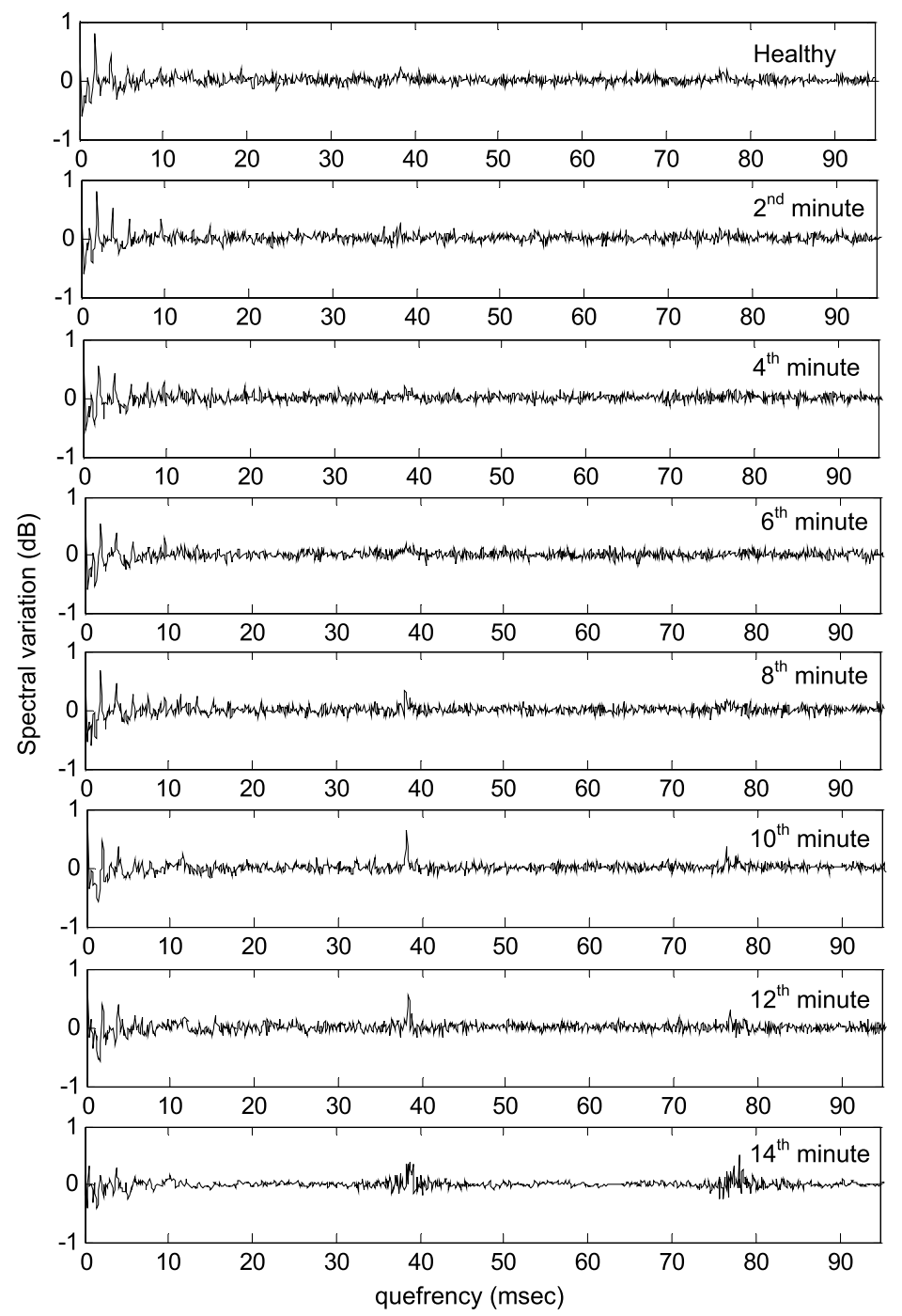

Fig. 11. Cepstra of the averaged gear vibrations monitored at two-minute intervals during the fatigue test. 

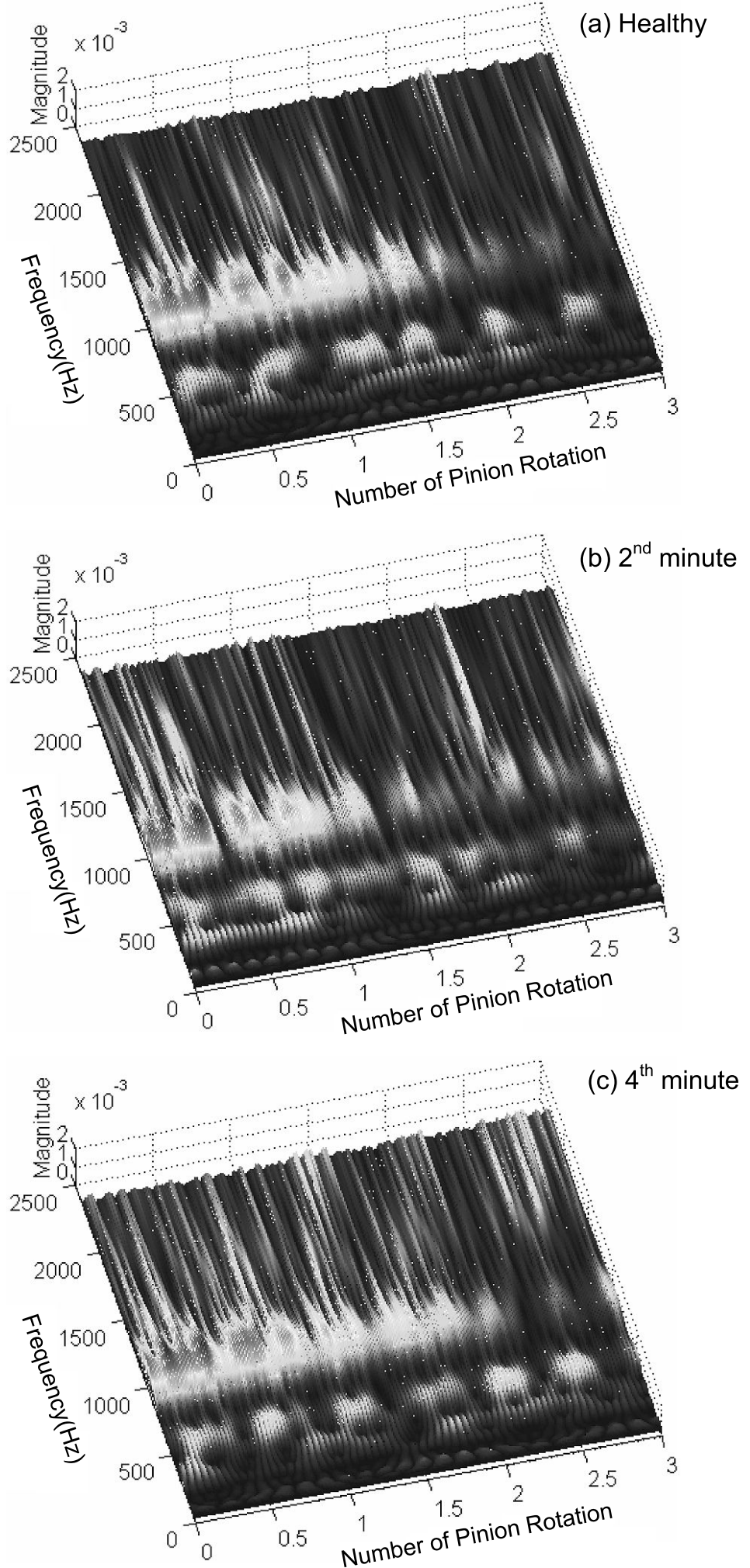

Fig. 12. Maps of wavelet transforms of the gear vibrations between $0-4$ minutes. 

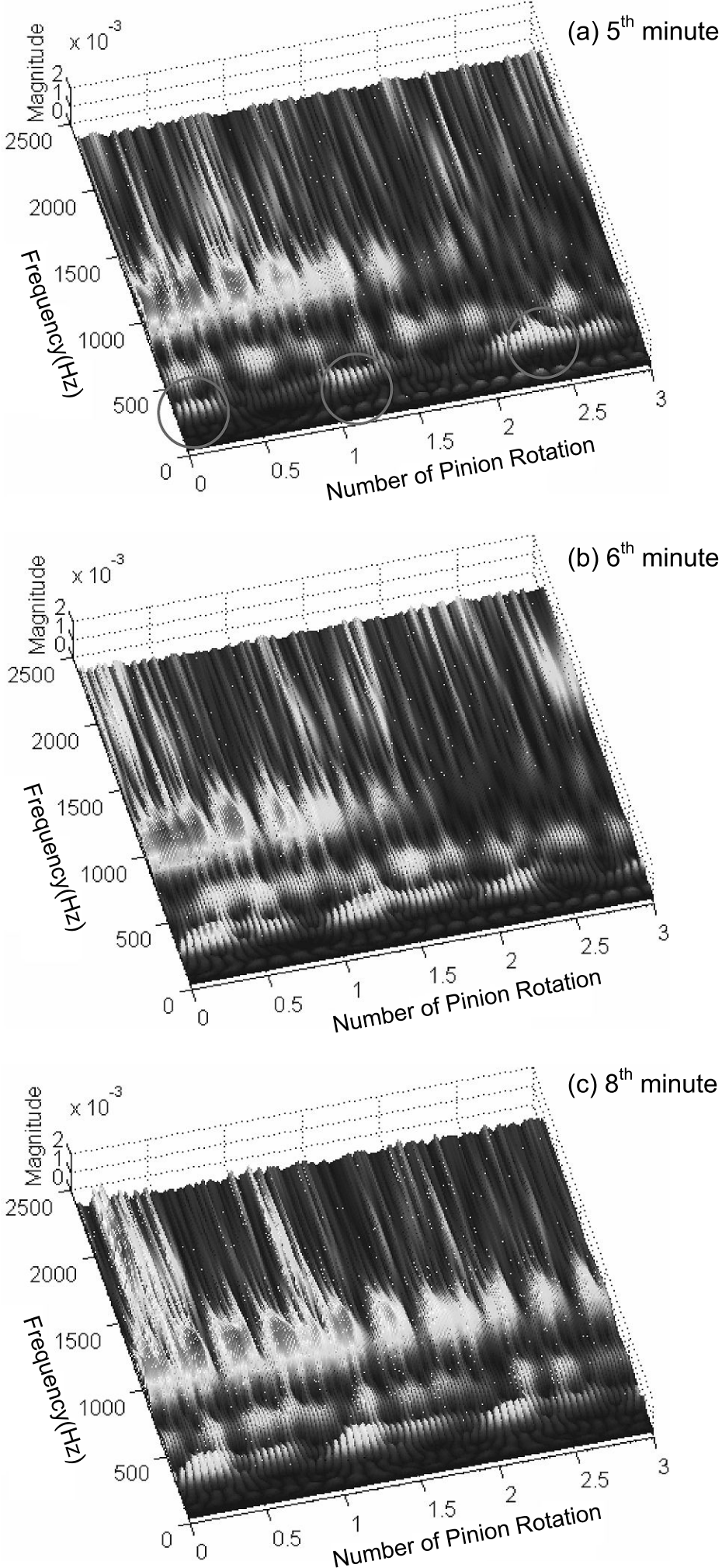

Fig. 13. Maps of wavelet transforms of the gear vibrations between 5-8 minutes (circles show the early indications of fault). 

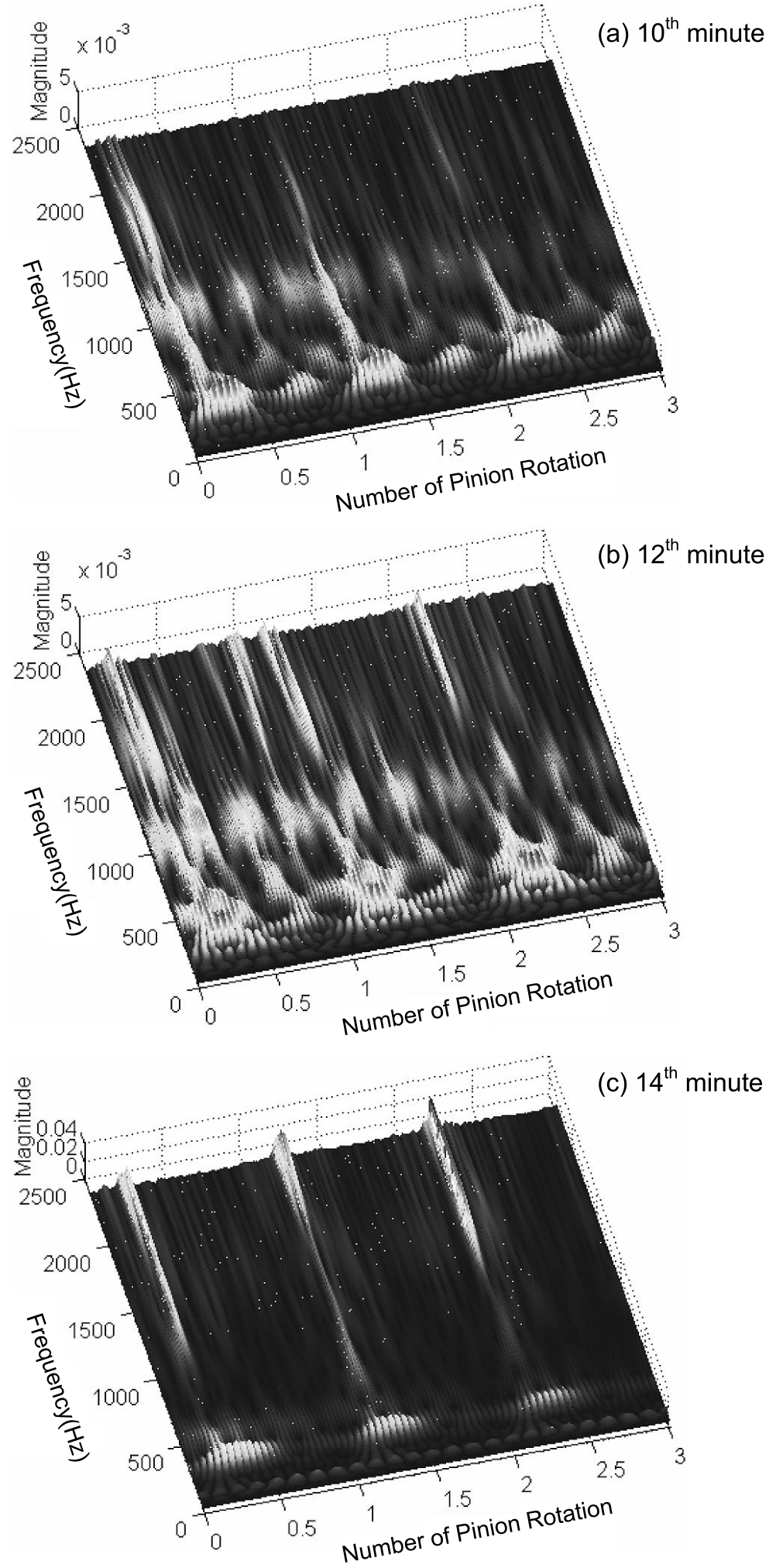

Fig. 14. Maps of wavelet transforms of the gear vibrations between 10-14 minutes. 
raised, whereas the low quefrency rahmonics yield diminishing amplitudes. This could be attributed to the fact that, as mentioned in Section 2.1, a pronounced localised gear fault not only gives a high intensity of amplitude modulation of the vibration signal only when the defective tooth (or teeth) is in mesh, but also decreases the total energy of the carrier frequencies which is indicated as reductions in the amplitude of the low-quefrency rahmonics. The resulting energy difference is consequently distributed to its finite number of sidebands which gives a rise to the amplitudes of the high-quefrency rahmonics.

\subsection{Wavelet analysis}

For the wavelet analysis, the residual vibrations (which are averaged over five pinion rotations) were used in order to improve the possibility of fault detection. The first 2048 samples of the averaged residual vibration signal were considered as the input to the wavelet transform, but only the results between columns 1 to 1930 of the wavelet transform matrix (which represents three pinion rotations) were displayed. During the wavelet analysis, the wavelet centre frequency of $f_{0}=1.0$ was selected, and to avoid a high calculation load, the octave band based fast calculation procedure was performed using 10 voices per octave. The resulting wavelet for each gear vibration was presented in the form of three-dimensional mesh plot. The wavelet transform was set to display the frequency content of the analysed signal up to $2500 \mathrm{~Hz}$, due to the fact that the frequency resolution of the transform diminishes with increasing frequency.

Figures 12 through 14 show the wavelet transforms of the averaged residual vibrations monitored until the end of the test and fault detection procedure is based on the visual observation of the wavelet transform. When the wavelet transforms of the resulting gear vibrations are compared, the early indication of fault condition can be distinguished at the 5 th minute of the test. At this time, the fault feature (which is most likely caused by the weakened tooth/teeth due to fatigue) manifests itself as a localised increase in magnitude around the $70^{\circ}$ gear position for nearly $300 \mathrm{~Hz}$ and repeats itself at every pinion rotation. After this time, the amplitudes of the wavelet transforms at the same gear positions are steadily increased with the advancement of time (e.g. until the 8th minute of the operation) which clearly reflects the progression of localised tooth damage. Pronounced fatigue damage diminishes the stiffness of the weakened tooth/teeth significantly which consequently causes the generation of stronger impulses only when the damaged tooth (or teeth) comes into mesh. The resulting fault symptoms are severe and mostly localised, and their presence is evident across a large frequency range starting from the 10th minute of the operation until the end of the test as seen from Fig. 14.

\section{Conclusions}

In this study, vibration-based techniques (i.e. conventional time and frequency domain approaches, cepstrum, and continuous wavelet transform) have been applied to real gear vibrations for the early detection, diagnosis and advancement monitoring of a real tooth fatigue crack in gears. It was found during the fatigue test that gear fatigue failure is an insidious type of gear damage which gives very little warning during it progression and cannot be easily detected by conventional time and frequency domain approaches until the fault is significantly developed. In addition, the use of residual vibration signal does not help very much with the early detection of fault, but only improves the visibility of fault features. Cepstrum analysis can be used for the detection of local tooth defects in gears, and it reveals the presence of fault earlier that the conventional time and frequency domain analyses. In contrast, the wavelet transform is quite sensitive to any change in gear vibration caused by local tooth defect and best reflects the progression of damage, hence can be used as the basis for early fault detection in gears.

\section{References}

[1] R.K. Mobley, An Introduction to Predictive Maintenance, Butterworth Heinemann, 2002.

[2] E.B. Boyer, Failure Analysis and Prevention, Metal Handbook, American Society for Metals, Ohia, 1975.

[3] J.K. Smith, Gear noise and vibration, Marcel Dekker Inc, New York, 2003.

[4] M.F. White, Simulation and analysis of machinery fault signals, Journal of Sound and Vibration 93(1) (1984), 95-116. 
[5] R.B. Randall, A new method of modelling gear faults, ASME, Journal of Mechanical Design 104 (1981), $259-267$.

[6] P.D. McFadden, Examination of a technique for the early detection of failure in gears by signal processing of the time domain average of the meshing vibration, Mechanical Systems and Signal Processing 1(2) (1987), 173-183.

[7] D.M Blunt and J.A. Keller, Detection of a fatigue crack in a UH-60A planet gear carrier using vibration analysis, Mechanical Systems and Signal Processing 20 (2006), 2095-2111.

[8] W. Wang, Early detection of gear tooth cracking using the resonance demodulation technique, Mechanical Systems and Signal Processing 15(5) (2001), 887-903.

[9] P.D. McFadden, Detecting fatigue cracks in gears by amplitude and phase demodulation of the meshing vibration, ASME, Journal of Vibration, Acoustics, Stress, and Reliability in Design 108 (1986), 165-170.

[10] J.E Nicks and G. Krishnappa, Gear fault detection using modulation analysis technique, Proceedings of the Second International Conference on Gearbox Noise, Vibration, and Diagnostics, Institute of Mechanical Engineers, UK,1995, pp. 81-89.

[11] G. Dalpiaz, A, Rivola and R. Rubini, Effectiveness and sensitivity of vibration processing techniques for local fault detection in gears, Mechanical Systems and Signal Processing 14(3) (2000), 387-412.

[12] R.B. Randal, Frequency analysis, Bruel \& Kjaer, 1987.

[13] H Tang, J-Z. Cha, Y. Wang and C. Zhang, The principle of cepstrum and its application in quantitative fault diagnostics of gears. ASME, Modal Analysis, Modeling, Diagnostics, and Control-Analytical and Experimental De-(38) (1991), 141-144.

[14] L.Cohen, Time - frequency distributions-a review, Proceedings of the IEEE 77(7) (1989), 941-981.

[15] C. Heneghan, S.M Khanna and A. Flock, Investigation the nonlinear dynamics of cellular motion in the inner ear using the short-time Fourier and continuous wavelet transform, IEEE Transactions on Signal Processing 42(12) (1994), 3335-3351.

[16] S.R. Qin and Y.M Zhong, Research on the unified mathematical model for FT, STFT and WT and its application, Mechanical Systems and Signal Processing 18 (2004), 1335-1347.

[17] W.J Wang and P.D. McFadden, Early detection of gear failure by vibration analysis-I. Calculation of time - frequency distribution, Mechanical Systems and Signal Processing 7(3) (1993), 193-203.

[18] Y.M. Zhan and A.K.S Jardine, Adaptive autoregressive modeling of non-stationary vibration signals under distinct gear states Part 2: experimental analysis, Journal of Sound and Vibration 3(6) (2005), 451-476.

[19] A. Belsak and J. Flasker, Detecting cracks in the tooth root of gears, Engineering Failure Analysis 14(1) (2007), 466-1475.

[20] F.K. Choy, V. Polyshchuk, J.J. Zakrajsek, R.F. Handschuh and D.P. Townsend, Analysis of the effects of surface pitting and wear on the vibration of a gear transmission systems, Tribology International 29 (1996), 77-83.

[21] T.A.C.M. Claasen and W.F.G. Mecklenbrauker, The Wigner distribution - a tool for time - frequency signal analysis, Part I: continuous-time signals, Philips Journal of Research 35(3) (1980), 217-250.

[22] C.P. Janse and A.J.M. Kaizer, Time-Frequency distributions of loudspeakers: the application of the Wigner Distribution, Journal of The Audio Engineering Society 31(4) (1983), 198-222.

[23] P.D. McFadden and W.J. Wang, Analysis of gear vibration signatures by the weighted Wigner - Ville distribution. Proceedings Institution of Mechanical Engineers, Journal of Mechanical Engineering Science (1992), 387-393.

[24] Q. Meng and L. Qu, Rotating machinery fault diagnosis using wigner distribution, Mechanical Systems and Signal Processing 5(3) (1991), $155-166$.

[25] C.J. Stander, P.S. Heyns and W. Schoombie, Using vibration monitoring for local fault detection on gears operating under fluctuating load conditions, Mechanical Systems and Signal Processing 16(6) (2002), 1005-1024.

[26] W.J. Staszewski, K. Worden and G.R. Tomlinson, Time-Frequency analysis in gearbox fault detection using the wigner-ville distribution and pattern recognition, Mechanical Systems and Signal Processing 11(5) (1997), 673-692.

[27] S.J. Loutridis, Instantaneous energy density as a feature for gear fault detection, Mechanical Systems and Signal Processing 20 (2006), 1239-1253.

[28] D.L. Jones and T.W. Parks, A resolution comparison of several time-frequency representations, IEEE Transaction on Signal Processing 40(2) (1992), 413-420.

[29] G. Meltzer and Y.Y. Ivanov, Fault detection in gear drives with non-stationary rotational speed-part I: the time-frequency approach, Mechanical Systems and Signal Processing 17(5) (2003), 1033-1047.

[30] N. Baydar and A. Ball, Detection of gear deterioration under varying load conditions by using the instantaneous power spectrum, Mechanical Systems and Signal Processing 14(6) (2000), 907-921.

[31] R.D. Hippenstiel and P.M. De Oliveira, Time-varying spectral estimation using the instantaneous power spectrum (IPS), IEEE Transactions on Acoustics, Speech, and Signal Processing 38(10) (1990), 1752-1759.

[32] I. Yesilyurt, Gear fault detection and severity assessment using vibration analysis, Ph.D. Dissertation, University of Manchester, 1997.

[33] I. Yesilyurt, Fault detection and location in gears by the smoothed instantaneous power spectrum distribution, NDT\&E International 36(7) (2003), 535-542.

[34] H. Ozturk, Gearbox health monitoring and fault detection using vibration analysis, Ph.D. Dissertation, Dokuz Eylul University, 2006.

[35] C.K. Chui, An introduction to wavelets: wavelet analysis and its applications, vol. I, Academic Press, Boston, 1992.

[36] C. Kar and A.R. Mohanty, Monitoring gear vibrations through motor current signature analysis and wavelet transform, Mechanical Systems and Signal Processing 20(1) (2006), 158-187.

[37] S. Loutridis, A local energy density methodology for monitoring the evolution of gear faults, NDT \& E International 37 (2004), $447-453$.

[38] G.Y. Luo, D. Osypiw and M. Irle, On-line vibration analysis with fast continuous wavelet algorithm for condition monitoring of bearing, Journal of Vibration and Control 9 (2003), 931-947.

[39] Y. Meyer, Wavelets: algorithms and applications, Society for Industrial and Applied Mathematics, Philadelphia, 1993.

[40] N.G. Nikolaou and I.A. Antoniadis, Demodulation of vibration signals generated by defects in rolling element bearings using complex shifted morlet wavelet, Mechanical Systems and Signal Processing 16(4) (2002), 677-694. 
[41] Y. Ohue, A.Yoshida and M. Seki, Application of the wavelet transform to health monitoring and evaluation of dynamic characteristics, Proceedings of the Institution of Mechanical Engineers 218 (2004), 1-12.

[42] Z.K. Peng and F.L. Chu, Application of the wavelet transform in machine condition monitoring and fault diagnostics: a review with bibliography, Mechanical Systems and Signal Processing 18 (2004), 199-221.

[43] W.Q, Wang, F. Ismail and M.F. Golnaraghi, Assessment of gear damage monitoring techniques using vibration measurements, Mechanical Systems and Signal Processing 15(5) (2001), 905-922.

[44] I. Yesilyurt, The application of conditional moments analysis to gearbox fault detection - A comparative study using the spectrogram and scalogram, NDT\&E International 37(4) (2004), 309-320.

[45] I. Yesilyurt, End mill breakage detection using mean frequency analysis of scalogram, International Journal of Machine Tools and Manufacture 46(3-4) (2005), 450-458.

[46] H. Zheng, Z. Li and X. Chen, Gear fault diagnosis based on continuous wavelet transform, Mechanical Systems and Signal Processing 16(2-3) (2002), 447-457.

[47] F. Hlawatsch and G.F. Boudreaux-Bartels, Linear and quadratic time - frequency signal representations, Signal Processing Magazine, IEEE (1992), 21-67.

[48] I. Yesilyurt and H. Ozturk, Tool condition monitoring in milling using vibration analysis, International Journal of Production Research 45(4) (2007), 1013-1028.

[49] H. Ozturk, M. Sabuncu and I. Yesilyurt, Early Detection of Pitting Damage in Gears using Mean Frequency of Scalogram, Journal of Vibration and Control 14(4) (2008), 469-484. 

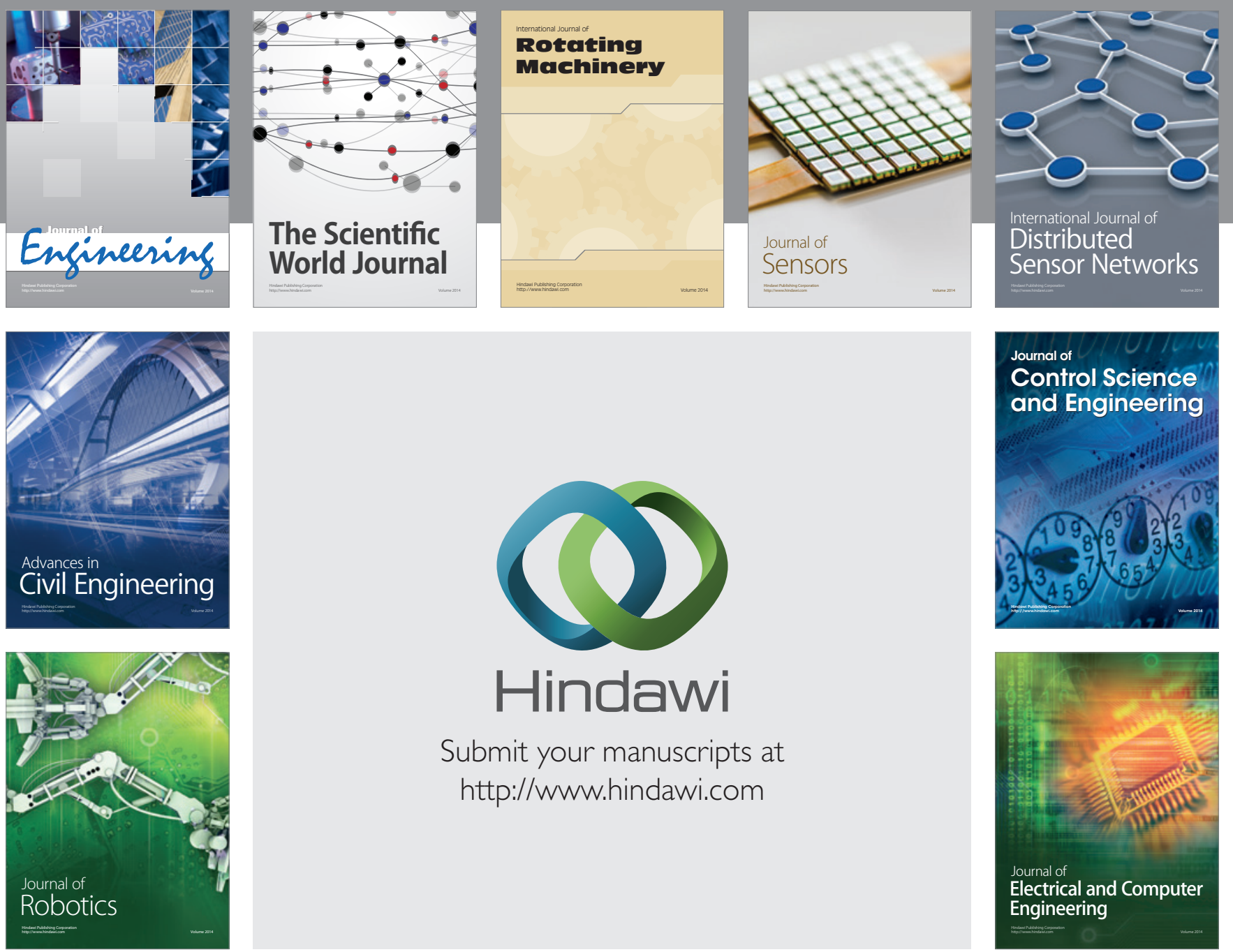

Submit your manuscripts at

http://www.hindawi.com
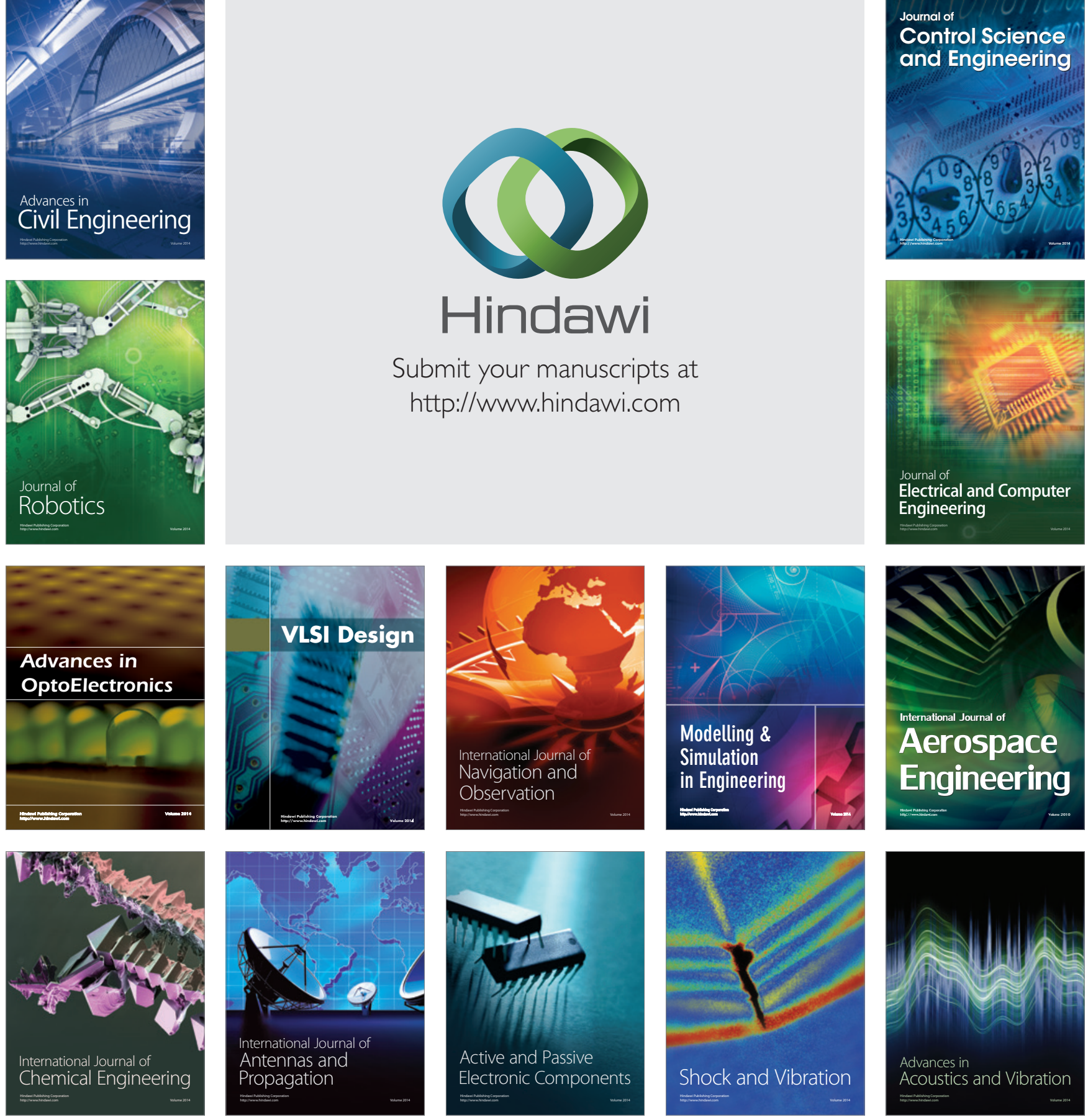